The Screenplay as Boundary Object.

Rosamund Davies, University of Greenwich.

r.davies@gre.ac.uk

\title{
Abstract
}

Described by Pasolini as a 'structure that wants to be another structure', the question of what kind of thing-in-itself the screenplay might be has produced a range of answers. Jean-Claude Carrière has used the metaphor of the chrysalis of vital importance in the process of the caterpillar's metamorphosis into a butterfly - but useless and empty once the butterfly, or film, has emerged. Sternberg has considered the screenplay's status as a 'second rank' text, in relation to the 'first rank' film performance. The idea of the screenplay as blueprint is common. Meanwhile, scholars (e.g Maras, Millard, Price) have raised issues with such definitions, pointing out their limitations. In this article, I propose the notion of the 'boundary object' as a useful way of thinking about the role and nature of the screenplay within the development and production of a screen narrative. My starting point is Star's concept of the boundary object, defined as an object that allows different individuals or groups with heterogeneous skills, knowledge and interests to cooperate towards a common goal by creating a 'shared space', situated at the boundaries between their habitual spheres of practice. I propose that, avoiding the problems inherent in an analogy such as the blueprint, it offers a useful starting point for understanding and analyzing the role of the screenplay in audiovisual production. 


\section{Main Article}

Described by Pasolini as a 'structure that wants to be another structure' (Pasolini 2005: 187), the question of what kind of thing-in-itself the screenplay might be has produced a range of answers. Jean-Claude Carrière has used the metaphor of the chrysalis - of vital importance in the process of the caterpillar's metamorphosis into a butterfly - but useless and empty once the butterfly, or film, has emerged (Carrière 2013). Sternberg has considered the screenplay's status as a 'second rank' text, in relation to the 'first rank' film performance (Sternberg 1997). The idea of the screenplay as blueprint is common. Meanwhile, other scholars (e.g Maras 2009, Millard 2010, Price 2010) have raised issues with such definitions, pointing out their limitations.

In this article, I propose the notion of the 'boundary object' as a useful way of thinking about the role and nature of the screenplay within the development and production of a screen narrative. Like the cases cited above, this particular definition of the screenplay provides a particular perspective on its role within the process of audiovisual production: focusing on how it might function (or indeed malfunction) as a site of cooperation and collective action. At the same time, however, this notion neither endorses nor negates any of the terms cited above. It maintains a certain openness. Whether or not a screenplay is a 'secondary text' or a work of literature, it may still function as a boundary object. 


\section{What is a boundary object?}

My starting point is Star's concept of the boundary object (Star 1989, 2010), defined as an object that allows different individuals or groups with heterogeneous skills, knowledge and interests to cooperate towards a common goal by creating a 'shared space', situated at the boundaries between their habitual spheres of practice (Star 2010: 602). In their paper of 1989, Star and Griesemer used the term to describe how the various stakeholders of an early $20^{\text {th }}$ century natural history museum (housed at the University of Berkeley, California), including professional scientists, amateur naturalists, trappers, farmers, patrons and administrators, managed to work together productively, despite the different social worlds they inhabited. These ways of working included the use of standardised methods and forms to collect relevant information along with every animal specimen. The forms allowed a range of people with different skills and interests to collect, index and curate effectively towards a common goal, making the information collected both comprehensible to each party and transferable between them.

Star and Griesemer also point to the state of California itself as an effective boundary object, for the reason that it was central to the concerns of all participants, while having particular meanings within each of their social worlds. This, they argue, is a crucial feature of a boundary object, which, by inhabiting different worlds simultaneously, can act as a 'means of translation' (Star \& Griesemer 1989: 393) between them. For the museum director, the focus on a defined geographical area gave him 'a delimitable laboratory in the field. For the 
university administration, regional focus supported its mandate to serve the people of the state. For the amateur naturalists, concerned with the flora and fauna of their state, research conducted within its bounds also served their goals of preservation and conservation' (Star \& Griesemer 1989: 409).

Star and Griesemer make the point that boundary objects can be both concrete or abstract and indeed (as with the State of California) are often both at the same time. Examples of common boundary objects include a 'repository' such as an archive or a database; 'standardised forms', such as a map, a template or proforma, as seen above. They may also be 'ideal types', such as a theory, concept or set of principles that 'serves as a means of communicating and cooperating symbolically'. (Star \& Griesemer 1989: 410)

What all these examples have in common is that they structure the sharing of information in a particular way, one that facilitates 'common communication across dispersed work groups' (Star \& Griesemer 1989: 411). One of the key features of boundary objects, underlined by Star, is that they constitute an arrangement that allows different groups to work together without consensus since they offer 'interpretive flexibility' (Star 2010: 602).

Another aspect to Star and Griesemer's notion of boundary objects is that they 'are weakly-structured in common use and become strongly structured in individual-site use' (Star and Griesemer 1989: 393). What they mean by this is that the various sub-groups involved in a large scale collective project will tend to generate tailored versions or off shoots of the original boundary object, for their own more specific use. 
Star also points out that all boundary objects, while they start off ill-structured, often chart a trajectory towards greater standardization, as their use becomes habitual and institutionalized. Such standardization, she suggests, is often driven by 'administrators or regulatory agencies', who seek to 'standardize and make equivalent the ill-structured and well-structured aspects of the particular boundary object' (Star 2010: 613).

\section{The screenplay as boundary object}

Following on from the discussion above, I would suggest that the screenplay could be considered to be a boundary object. During the process of development and through to post-production, screenplays are read by many different readers, including agents, producers, financiers, script analysts, actors, directors etc. (Sternberg 1997). These individuals each have different motivations and use the screenplay in different ways, as a means to realise both the economic and creative potential of the 'screen idea' (Macdonald 2004). It serves as a standardised form, in which the same standard elements of the script: sluglines, action, description, dialogue, characters, lend themselves to different concerns and uses. While these properties of the screenplay might equally be used to advance the idea of it functioning as a blueprint, I want here to emphasise its role as a site of action and negotiation, suggesting that, as a structure, it offers 'interpretive flexibility', making information both comprehensible to a wide range of actors and interests within a project, and transferable between them. People read screenplays, discuss them, provide notes on how to change them; they use them as a starting point for taking one course of action or another, and 
also to try and influence or change the actions of others.

In development, a screenplay might provide the starting point for an agent to explore the script's star vehicle potential with a client, while on the other hand it might cause a producer to reject it because of its genre or budget requirements. The screenplay is the starting point for a production manager to budget the film, and the First $\mathrm{AD}$ to schedule it, as well as being the initial inspiration for the director, designer, cinematographer, actors and other key creative contributors to a screen narrative. They may also make notes on their script as part of the process of translating it to the screen. During the shoot, the script becomes a kind of repository, in which the script supervisor will keep a note of how things change, providing a revised and marked up script for the editor. The screenplay, in both conceptual and material form, provides a shared space at the boundaries between the habitual spheres of practice of all these different contributors, which can provide a 'means of translation' between them as they work towards the realization of the screen idea. The fact that all of this can happen without necessitating any absolute consensus is something which can both help and hinder the process, as I will go on to discuss later in the article.

\section{The notion of the boundary object within screenwriting studies}

As I indicated at the outset, the notion of the screenplay as boundary object does not exclude the use of other terms to define the role of the screenplay within the production process. Just as an architectural blueprint functions as a boundary object, so too can a screenplay, whether considered as a kind of blueprint, or as 
anything else. Since the term 'boundary object' is a loose category, rather than an analogy between one thing and another, it offers a certain openness interpretive flexibility in fact - which an analogy lacks. As Maras has pointed out, while the conception of the screenplay as blueprint is in many ways useful, the analogy offers a dangerous invitation to close the gap between the thing itself and that to which it is likened. The result is an overly narrow interpretation of how a screenplay functions, which fails to acknowledge that 'the shape and structure of the material can be negotiated along the entire length of the production process' and 'suggests a technical idea of precision, embodied in a diagram, [whereas] a script works as a blueprint not because it is technically precise, but because it is poetic.' (Maras 2009: 124). The blueprint analogy can thus alternatively underplay the role of the writer, suggesting 'that the screenplay is of value only as a set of practical guidelines' (Price 2010: 46), or overstate the writer's creative input, since it can also be used to suggest that, while the writer conceives of an original idea, the rest of the creative team merely executes it, an interpretation that minimises the role played by many another contributors in the creation of the screen work. (Maras 2009)

One of the useful aspects of the notion of the 'boundary object' is that rather than an analogy for the screenplay, it provides a framework for its analysis, situating it within a wider context of action, beyond its relationship with the writer or writers, to also include the relationship that it facilitates between the wide range of people who make up the 'screen idea work group' (Macdonald 2010). As a concept, it provides a starting point both for thinking about how the particular form taken by the text relates to its function as a site of cooperation between 
these various actors, and also how this range of different participants in a screen production actually use the screenplay in practice to facilitate discussion and collective action, without them all needing to meet, or indeed to reach a consensus.

I want to make clear that a focus on the screenplay as boundary object does not negate the validity of an analysis of the screenplay as text. The screenplay, while it may be a 'structure that wants to be another structure' (Pasolini 2005: 184) is also not that other structure, and can be analysed as a text that exists separately and differently from its audiovisual realization and also without necessarily focusing on its functional role within production.

Beyond that, however, the textual qualities of the screenplay are equally an important aspect of its role within audiovisual production and of how it functions as a boundary object. Within the contemporary audiovisual production industries, it is the capacity of the 'reading script' to represent on the page, using literary techniques, the dramatic and cinematic qualities that will animate the final film or television narrative, that make it such an important element in the package that a producer or agent promotes to a studio, television channel or other content platform. Indeed, Rush and Baughman (1997) have highlighted the level of nuance and complexity that can be achieved through the use of narration in a screenplay. They analyse, for example, the way that the narration of events in the screenplays for Blue Velvet (Lynch (Wr.) 1984), The Player (Tolkin (Wr. 1992) and Heathers (Waters (Wr.) 1988) guide the reader (e.g key collaborators such as producer, director, production designer, actors etc.) to seek meaning not so much in the unfolding of the events of the story but rather in 'the tension 
between events and their telling' (Rush \& Baughman 1997: 30) Their argument here, like that of Maras above, is that it is the literary or poetic qualities of the screenplay, as an initial crystallization of the screen idea, which inspire further stages of crystallization through the work of other collaborators (Maras 2010: 124).

Another interesting aspect to consider is the significance of the screenplay as a weakly-structured boundary object, in the sense that the particular components of its form represent a compromise between the different kinds of logistical and aesthetic information it needs to convey to the wide range of people cooperating on a project. It is not too tightly tailored to the needs of any one individual or community of practice involved in the project, but has evolved to provide a shared space where all their needs can be represented, and cooperation between financers, production team, director, actors, camera, design and other departments can be managed. It is important to recognize that, in Star's conception, this is a process of achieving cooperation by managing tension (Bowker \& Star 2009) and absence of consensus (Star 2010) between participants, rather than eliminating it. The assumption is that what all these actors in the project think they are doing, how they would define the nature of the project, the rationale for why they are doing it and what they aim to get out of it is not identical, indeed they may have quite conflicting motivations. As Macdonald emphasizes, cooperation between members of the screen idea work group is not necessarily a collaboration based on consensus. It may, moreover, become 'less of a negotiation and more of a power struggle' (Macdonald 2010: 
52), making some members of the group unhappy about the process. This does not necessarily mean, however, that cooperation is not achieved.

Since the screenplay is not perfectly suited to every need that any particular individual or more specialized community of practice involved in the project might have, participants will produce more strongly-structured boundary objects that relate to the script but are more closely tailored to their needs. Common examples might include financial models run by investors, budgets, shot lists, storyboards, shooting scripts, prop lists etc. They will also adapt the script by annotating it, as mentioned above. As they cooperate together on the project these sub groups will 'tack back-and-forth' (Star 2010: 605) between these objects and the screenplay as the boundary object that is common to all groups. Investigation into how a range of 'strongly-structured boundary objects' (Star \& Griesemer 1989), such as financial models, budgets, storyboards etc. are used in relation to the screenplay could be an interesting line of enquiry. The weight each carries, how they are brought into dialogue with each other etc. are aspects that could be examined.

It would also be worth investigating further the relationship between the screenplay as boundary object and the screenplay as standardizing mechanism. I have already defined the screenplay as a standardized form and the 'standard screenplay format' is dominant in the industry. This is the result of the long history of some form of script, scenario, outline etc. being used as a central boundary object within film and television production. Over time this form has been honed and reified to suit the changing needs of this industry, as it has 
evolved (Staiger 1985, Maras 2009, Price 2010), and has been subject to the drive towards standardization that Star describes, although it also continues to evolve (Millard 2010, 2014). This process of standardization has produced a form that is many ways very effective, still offers interpretive flexibility and facilitates cooperation across the range of people and groups involved in an audiovisual production. However, the move towards standardization also presents problems. As Star suggests, when discussing boundary objects in general, the problems of standardization often lie more in what it works to exclude: what material and approaches are rejected or disregarded, because they do not fit within its parameters. As she points out, 'standards make "others" ' (Bowker \& Star 2000: 609)

A particular feature of the screenplay, in contrast to many other boundary objects, is that one of the main ways in which it is used to realize the screen idea is through an iterative process of reimagining and altering its own content and form. During script development, the screenplay functions as both a key space of collaboration and as its temporary end goal. At this point, another boundary object comes into play - what Macdonald (after Bourdieu) has called the doxa (Macdonald 2010) and Millard a template (Millard 2010), i.e normative conceptions of what constitutes an 'ideal type' of script. In addition to formatting rules, this 'ideal type' is likely to comprise such story aspects as one central protagonist, a clear line of cause and effect, a certain number of acts (guidelines vary from 3-8), a transformation in the central character from beginning to end, etc. 
While there is a clear rationale for working to this kind of template, since it has proven to produce screen narratives that appeal to audiences (and indeed often also to critics), equally, many screen narratives succeed in attracting large scale audiences without including all of these aspects, although they may well include some of them. Within the discourse of script development, however, the goal of producing an ideal script might seem sometimes almost to replace the goal of producing the successful screen narrative that it imagines (Millard 2010, Murphy 2010). This can be seen as both a product and a cause of the fact that a large percentage of script development, whether practised by studios, offered as a commercial service, or part of public funding schemes, is speculative and disassociated from any direct route to production. In this context, script development becomes 'an end in itself' (Millard 2010: 13), risking a fetishization of the form of the script that limits its actual usefulness. Furthermore, as Star points out, the aim of standardization is more often control than cooperation (Bowker \& Star 2000). A set of standards is usually too inflexible to function as an effective boundary object. Excessive standardization of a boundary object reduces or eliminates its interpretative flexibility, thus making it less effective at achieving cooperation and directed more towards compliance (Bowker \& Star 2000). Within the process of script development, it can happen that the screenplay ceases to function as a (fairly weakly-structured) boundary object, through which to negotiate the screen idea, becoming instead so strongly structured that it functions as a mechanism through which to make sure that both script and writer conform to a set of standards. 
A related line of enquiry concerns how alternative scripting forms might facilitate the inclusion of material that is excluded from standard screenplay formats and how their use might support a different kind of collective development of the screen idea, within a different kind of screen idea work group than the one facilitated by the standard screenplay format. A fourth area of interest is the extent to which various kinds of conceptual constructs, such as market expectations, genre conventions, and other cultural assumptions, also function as boundary objects - 'ideal types' (Star and Griesemer 1989) - which, while not explicitly represented in the screenplay, are implicitly negotiated through it. I will elaborate on these latter two examples below.

\section{Alternative scripting documents and processes}

I have previously described how the development documents that Marguerite Duras produced during the development and production of the film Hiroshima Mon Amour (Duras/Resnais 1959), took different forms at different moments of the process and how the nature of these forms related to the nature of the collaboration between Duras, the writer and Resnais, the film's director (Davies 2010). What I particularly want to flag up here is Resnais's statement that what he was looking for in Duras in particular as a writer was that she 'had tone' (Davies 2010). To capture this, in addition to an initial screenplay provided by Duras, he asked for recordings of her reading the dialogue to certain sections of the screenplay, which he played to the actors before they performed them, in order for them to internalise the rhythm and intonation he wanted to achieve in these scenes. These recordings might be seen as providing even more of a 'blueprint' than the screenplay itself. At the same time, however, they also 
offered material - the sound of the human voice - that is excluded from the textual materiality of the screenplay. At a later point in the production, before shooting the sequences of the film that were shot in the town of Nevers, France, Resnais asked Duras to write prose 'commentaries' on different scenes, as if she was describing a film she was already watching (Davies 2010). These 'commentaries' are prose passages, novelistic in tone. Duras writes, for example, 'late one afternoon, a German soldier crosses a square somewhere in the provinces of France. Even war is boring.' (Duras 1966: 84), or describes the town of Nevers in the following terms: 'the wheat is at its gates, the forest is at its windows. At night, owls come into the gardens and you have to struggle to keep from being afraid' (Duras 1966: 86). These passages are not formulated to facilitate any direct translation to the screen. For Resnais, however, seeking above all to render a cinematic version of Duras's tone and sensibility, they clearly provided an effective 'means of translation' (Star \& Griesemer 1989: 393) between the literary world that Duras inhabited (this was her first screen work) and the cinematic (but until then documentary) world that Resnais inhabited, that was not accessible through the original screenplay.

This employment of prose narrative in addition to the screenplay form is also present in the collaboration between writer Jon Raymond and director Kelly Reichardt on the film Old Joy (Murphy 2011). Reichardt says of their collaboration that 'it's a perfect match, in that he writes these really interior kinds of characters, and then the challenge for me is just figuring out how to physicalize that in turning things over into a script' (Murphy 2011: 160). She seems to be suggesting that one of the key differentiators of prose as a form of 
writing, compared to the screenplay (its ability to develop and dwell on interiority) is precisely what she values as an inspiration for her own vision as director. Just as for Resnais, cited above, the story in prose fiction form seems to give her a depth of material to work with that she needs, but which would not be available in a screenplay format. It establishes a distance, a productive gap between the writer's voice and her own, which seems then to become the shared space of collaboration. Raymond also suggests that what the short story might offer is a particular 'sense of time', which is a feature of his writing, and which Reichardt also brings to her films: 'Neither of us seems to mind letting certain moments expand, and we don't need too much narrative activity to keep us interested' (Murphy 2011: 160). It is also notable that Raymond's short story was originally inspired by a set of photos by Justine Kurland (Murphy 2011: 160). The process of poetic 'crystallization' (Maras: 124), or of creative translation, is very clear here. The short story and the collection of photographs offer different affordances ${ }^{1}$ as boundary objects than does the screenplay.

It is notable that Reichardt and Raymond did then collaborate to produce a screenplay version of the story with which to go into production. Murphy does not elaborate on the various reasons for this, but it is likely that it constituted a more manageable boundary object with which to negotiate with a wider range of collaborators. The boundary objects that facilitate collaboration between writer

\footnotetext{
${ }^{1}$ The term 'affordance' is used in design theory and practice to describe the particular properties of an object that suggest to a potential user how to use or interact with it. By using this term, I mean to underline the fact that the form taken by the script or scripting document is significant in suggesting and shaping the nature of the collaboration or 'creative translation' that it facilitates.
} 
and director are not necessarily an appropriate basis on which to site wider cooperation.

At the same time, of course, many audiovisual productions, particularly with small crews and cast, do go ahead without a screenplay, working instead with a story outline and lists of sets and props along with improvised performance, for example (Millard 2010), or notebooks of words and images, or other kinds of 'graphic screenplays' (Munt 2012: 62). Such case studies highlight the way that working with planning documents other than screenplays facilitates particular kinds of cooperation: a director working with non-professional actors, for example, or with the intention of achieving episodes of 'psychodrama' rather than scripted performances (Murphy 2010).

\section{Implicit negotiations of excluded material}

Another thing to look at is the extent to which various kinds of priorities and assumptions are implicitly negotiated through the standard screenplay format, despite their explicit exclusion. In fact, I first became interested in the idea of the screenplay as boundary object and employed it as an analytical framework, while acting as a script editor for an educational videogame project called Maritime City. I became aware that the screenplay was not actually working very well as a site and tool of cooperation between parties in the project, precisely because priorities and assumptions that had not been explicitly articulated were being implicitly negotiated through the script (Davies 2014). To illustrate this I will point to the example of one draft script for a certain sequence of the game, to which the response of the health educators within the screen idea work group 
was that, while they liked the script, they wanted to remove all the choices offered to the player. Since the structure of the game was a branching tree structure driven by choices, this was clearly an unworkable suggestion for the screenwriters. They couldn't understand why the health educators seemed to want to sabotage the game.

In the end, it turned out that it wasn't actually the structure the health educators were objecting to, but rather the content of the choices. Their objections related to particular priorities within child protection, which were central to their aims for the game but which they hadn't actually communicated to the writers. The health educators felt that the choices didn't relate to these priorities. However, when using the screenplay as the primary means of cooperation for the videogame, unfamiliarity with the form meant that it was difficult for the health educators to separate out the choice as structuring mechanism from the actual content of each choice, which was the real problem. Implicit discussions about best practice, appropriate messages etc. thus became displaced into discussions of form and structure, leading them to see removing the choices altogether as the only solution. To people familiar with the conventions and processes of screenwriting, and with how documents such as the screenplay are used within it, this might seem hard to understand. However, as Star points out 'People often cannot see what they take for granted, until they encounter someone who does not take it for granted' (Star \& Bowker 2000: 291). The transparency of the script format as a mode of communication was so much a given for the script professionals on the project that they had failed to recognize the potential implications of the health professionals' unfamiliarity with the form and with 
how to manipulate it. Likewise, the health educators' priorities existed in the form of tacit knowledge, taken so much for granted that it was hard for them to realize the importance of articulating it to people outside their profession. The result was that considerations that were central to the cooperation between parties were being negotiated through the screenplay implicitly rather than explicitly. Once the real issue was made clear, it was possible for all parties to agree to the branching tree structure being reinstated with new choices.

Although the above example details problems arising from working with collaborators from outside the film and television, this kind of implicit negotiation can also cause problems in the mainstream film and television industries. In addition to being a boundary object in its own right, the screenplay is almost always also functioning as a proxy for other boundary objects, particularly those that are more conceptual in nature.

Screenwriter Craig Mazin has discussed the prevalence of 'inorganic notes' that are often a feature of the development process (Mazin 2018). Contradictory concerns and demands that play into the development process, often result in screenwriters being asked to deliver the impossible. The point made by Mazin is that it is the implicit nature of these concerns that are the problem. Just as in the educational videogame case, one set of concerns is being displaced onto another. Market expectations or budget concerns are being expressed as notes on character and plot. Mazin argues that if development executives made these concerns explicit then the problem would largely be solved and they would be able to cooperate much more successfully with screenwriters. 
However, as Anamik Saha points out, drawing on Havens' concept of 'industry lore' (Saha 2018), the kinds of market considerations cited by Mazin are often bound up in cultural assumptions which remain unconscious and unacknowledged. Supposedly commercial imperatives themselves often function as a kind of proxy for tacit cultural assumptions. Saha argues that such assumptions constitute more than the personal bias of particular creative managers, rather they are embedded in the core rationalization strategies of the cultural industries: 'bureaucratization, formatting, packaging and marketing' (Saha 2018: 130). According to Saha, the term bureaucratization describes the combination of 'both written forms of policy (rules, codes, best practices, memos, manuals, trade magazines)' and the unwritten cultural values of a particular institution, through which it disciplines its workers in a non hierarchal way to adopt and indeed internalize certain codes of behaviour (Saha 2018: 130). Industry conventions of what constitutes good storytelling and a correctly formatted script that are promoted as marking out the 'professional' from the amateur can be seen as a form of this kind of bureaucratization.

They are also of course an example of formatting - 'creating a cultural text according to a production format or formula' (Saha 2018: 131). The motivations behind such formats and formulas are closely connected with industry lore relating to audience preferences. These assumptions are hard to shift. Drawing on Havens (2013), Saha points to the example that, for a long time, industry lore held that screen narratives involving central protagonists of colour would not appeal to white or international audiences (Saha 2018). The success of The Cosby 
Show did nothing to shake this conviction, but was explained 'in terms of its universal family themes, which supposedly transcend race. In other words, television executives produced a lore that suggested that The Cosby Show was a success in spite of its blackness.' (Saha 2018: 122 my italics). This led to an increase in commissioning of conservative family sitcoms involving nonblack characters, rather to any more sitcoms with black casts. The surprise crossover and international success achieved by The Fresh Prince of Bel-Air, however, did finally start to change industry lore, 'whereby executives began to consider how the particularities of African Americanness, rather than alienating foreign audiences, can actually resonate with them in a number of ways' (Saha 2018: 122).

The artefacts, templates, ideals, theories and beliefs discussed above can be considered to be boundary objects in their own right. When, during the process of script development, they become the reference points for how to shape the screenplay, they themselves become sites of cooperation - or indeed of conflict. The successful cooperation of the screen idea work group on the script depends on the interpretive flexibility of these other boundary objects - whether they are meaningful and relevant to all parties, or can at least be negotiated to be so. As suggested above, this does not always happen. Millard's account of finding that, as an independent filmmaker, her interest in 'ambiguity, internalized character conflict, and visual motifs as structuring devices' (Millard 2010: 12) could not inhabit a shared space with the storytelling principles promoted by the Australian Film Commission, provides one example. Another is provided by producer Stephanie Allain, who describes the way that narrow conceptions of 
what kinds of BAME characters are suitable as central protagonists can restrict the variety of screenplays that are commissioned:

'The awards-targeted films today that get a minority protagonist tend to be about the most amazing person of that race who's ever lived. But award movies with white protagonists are just about a white person who did a thing: It's a white dude who fought a bear, it's a white lady who lives in Brooklyn, it's a white lady who invented a mop...' (Bernardin 2016)

As cited above, even Mazin, a white, male, Hollywood insider, complains about the difficulty of negotiating implicit imperatives. It seems clear that such implicit boundary objects, operating through and in addition to the screenplay, are the often unacknowledged site of much misunderstanding, conflict and restriction of opportunity.

My intention here is not to simply suggest that such rationalization be abandoned, which is unlikely and impractical, nor to suggest that standard storytelling conventions have no merit. My point, following Saha and Star, is, first, to highlight the extent to which the rationalization/standardization strategies described above can provide vehicles for unexamined cultural bias and stereotypes relating to race, gender, sexuality and other forms of 'otherness'. These both exclude marginalized groups from participating in cultural production and, even when they are included, tend to oblige them, and all cultural workers, to perpetuate certain forms of representation in favour of others. 
Second, rationalization strategies frequently have the unintended consequence of ironing out the very qualities of originality that audiovisual content commissioners repeatedly say they are seeking. Instead they establish a set of standards that achieve conformity (thus minimizing the need for any cultural gatekeeper to take any obvious risk or assume too much personal responsibility in developing, financing or marketing a product), but fail to encourage the innovation on which creative production depends (Millard 2010). There needs to be an explicit acknowledgement of the cultural assumptions and interests that are embedded within 'supposedly neutral commercial reasoning' (Saha 2018: 140). With specific reference to the context of script development, there needs to be a recognition that the screenplay as boundary object usually functions as a proxy for a number of others. This can become a very tangled knot to unpick.

\section{Successful negotiation of implicit boundary objects}

However, it can also work in a productive manner. As one example, I would point to a common boundary object used within the development of the screen idea and the production of the screen work, the genre. The Nordic Noir genre was a key boundary object for the Icelandic TV series Ófærð/Trapped (2015) and an example of interpretive flexibility in action. Like the state of California, cited by Star and Griesemer, the aim of producing a 'Nordic Noir with an Icelandic twist for an international audience' was a concept that was meaningful for a range of participants cooperating on the project, while not meaning exactly the same thing to all of them. In the beginning these included the German television 
channel ZDF, the German/French executive producer and the Icelandic creators: writer/director Baltasar Kormákur, and screenwriter, Sigurjón Kjartansson. Kormákur, both from production company RVK Studios. For the latter, a key aim was 'putting Iceland on the map' (Kjartansson 9 September 2016 interview). For the financers and executive producer the key interest was the international market potential (Zimmermann 31 May 2016 interview). As the project progressed, the screen idea work group expanded to include a British writer, Clive Bradley, and a French script editor, Sonia Moyersoen. Here again, the shared boundary object of Nordic Noir with an Icelandic twist for an international audience provided a logic and a framework for the expansion of the writing team beyond the original creators that everyone could sign up to. Since the British screenwriter had more experience in writing crime drama for an international audience, and the script editor had experience on international coproductions, which the Icelandic creators did not, the latter could understand that these team members could help to facilitate the overall aims of the project (Kjartansson 2016).

Despite their different cultural backgrounds, the broader concept of Nordic Noir provided some general guidelines on how to structure the overall story arc, characters, treatment of setting etc., meaning that a British writer and a French script editor could successfully develop a story set in a culture that they did not know (Bradley 23 March 2016 interview). On the other hand, the 'Icelandic twist' aspect of the premise meant that primacy was given to the Icelandic writer on the project, with regard to the cultural context, even if cultural considerations seemed to go against the conventions of the genre. For example, Bradley wrote 
an episode, in which the main protagonist, a police detective, goes back home after a challenging day and pours himself a glass of whisky. However Kjartansson suggested that instead he drink a glass of milk, objecting that the whisky would signify that he was an alcoholic (Kjartansson, Bradley, Moyersoen 2016). This would not necessarily be the case for many sectors of the international audience, in France or Britain for example, and this was not Bradley's intention. He was in fact adhering to the conventions of the crime genre, within which the harassed detective pouring her or himself a glass of whisky is fairly commonplace. But Kjartansson explained that in Iceland people only drank at the weekend and so, if the detective were to drink during the week, within the world of the film and for the Icelandic audience, this would signify an alcohol problem. The other members of the writing team were able to accept that this was an important consideration, given the overall aim of the project. Because the genre and cultural parameters had been clearly articulated at the beginning of the project, they were able to identify them explicitly and understand and make use of the screenplay as a boundary object through which to negotiate them.

Another example from international co-production comes from the development process on Italian/British/US co-production Medici (2016-). Creative Producer, Luisa Cotta Ramosino, states that the series needed to somehow find a shared space between Italian and British/American traditions of historical drama, which she defines as 'Italian didactic approach versus American British entertainment' (Cotta Ramosino 12 January 2019 interview). The partners were aware of this difference from the start. Indeed, the desire to take a less didactic and more entertainment approach, in order to target an international audience, was one of 
the reasons why Italian production company Lux Vide wanted to work with Europe based American writer, Frank Spotnitz, the series creator (along with Nicholas Meyer), and why the series was written and shot in English by mostly British writers. However the practical implications of this aim only came out fully during the course of the production. One difference was the attitude to historical facts. Italian historical drama 'has a tradition of historical fiction that tends to be more faithful to the sources' (Cotta Ramosino 2019), and the series was dramatizing Italian history that she says is 'really part of our identity.' How to find 'a compromise between being faithful to the history and creating a compelling story', which was acceptable to all co-production partners, became the central negotiation of the script development process, through which the story and characters were ultimately developed with greater freedom in relation to the historical facts than they would have been within an Italian national context (Cotta Ramosino 2019). Cotta Ramosino says that initially the Italian television network RAI, a major financer of the project, and a veteran of coproductions (Buonanno 2015), accepted that 'it wasn't going to be a perfect Italian series, but this would make it a better international series' (Cotta Ramosino 2019). While the project was pushing against one kind of 'industry lore' about national audience preferences, it conformed to another one about international audience preferences, and so was able to assuage the concerns of the Italian television network, creating the necessary shared space between them and their UK partners.

However, in the end the series was very successful with Italian audiences, as well as international audiences. In addition, many Italian viewers watched the 
original English language version (which RAI made available on a digital channel), rather than the official Italian language version of the series (which was also highly successful) (Cotta Ramosino 2019). This is in line with a preference amongst younger Italian viewers for watching English and French language imported series in the original language rather than dubbed into Italian (Buonanno 2015). It will be interesting to see the extent to which such audience preferences might begin to reshape the priorities that currently guide Italian national commissioning strategies.

Another relevant point that Cotta Ramosino makes refers to the way that the writers' room developed a particular language for the dialogue in the series. This was not something that was planned beforehand, but emerged through the script development process. Cotta Ramosino, who is herself a writer, acted as a liaison between the British writers' room and the Italian production company Lux Vide, reading the draft scripts and feeding back to the room. She felt that the tone and feel of the dialogue in the first script drafts wasn't quite right, it needed to have a bit more weight and cultural specificity. She wanted it to sound a little less modern and colloquial, while at the same time 'we didn't want to have it like ancient poetry or something' (Cotta Ramosino 2019). The need to strike the right balance extended also to the use of words that had historical specificity: a word like 'democracy', for example, would mean something quite different to the Renaissance characters than it would to a modern audience. It was necessary to choose words quite carefully and not go for the obvious ones, in order to really convey the fact that 'the ideas they [the characters] were talking about were different from ours' (Cotta Ramosino 2019). The way Cotta Ramosino and the 
writers worked this out was by trial and error, through writing and reading different script versions and having discussions about how the dialogue seemed to be working. She says it was 'an interesting way of exchanging ideas about it and getting to know the culture better'(Cotta Ramosino 2019). One of the approaches they hit upon was integrating some Italian archaic terms of address, such as 'Madonna' and 'Messere' into the English language dialogue of the screenplay. According to Cotta Ramosino, both she and the writers found this an enjoyable process. She cites the fact that the writers took to playfully calling each other 'Madonna' or 'Messere' within the room. The process of creating the right language for the series seemed to make the world come more fully alive for the writers, giving them a stronger sense of connection to the Italian history they were dramatising. Cotta Ramosino sees this establishment of a particular language for the series as one of the key ways in which the development process managed to establish what she calls a 'free zone between Italy and UK' (Cotta Ramosino 2018). This is an interesting example of the different ways in which the screenplay functioned as a boundary object within the project, establishing a shared space of cooperation between the co-production partners.

\section{Conclusions}

To conclude, I hope that, through the arguments and examples elaborated above, I have provided some insights into the ways in which the concept of the boundary object can contribute to the study of the screenplay. It offers a useful framework for thinking about the role of the screenplay in audiovisual production, which, while not incompatible with analogies such as the blueprint, 
avoids some of their inherent problems. It is particularly useful as a way of understanding and analysing the screenplay and associated development documents as sites of cooperation and action, both in relation to the particular form that they might take and the way that they are used by those cooperating to develop and produce a screen narrative. Such an analysis is not limited to the study of successful and smooth collaborations. The concept of the boundary object was specifically developed by Star as a way of understanding how people manage to collaborate in the absence of consensus. It lends itself equally to the study of difficult negotiations and instances of conflict within the development and production of a script, and to occasions where 'interpretive flexibility' breaks down. This potentially includes examples of how this can be caused by the drive towards standardization.

Furthermore, the notion of the boundary object is applicable to a wide range of scripting formats and approaches and not just to the standard industry screenplay format. It is a useful starting point for thinking through the relationship between particular scripting formats and approaches and the particular development and production processes in which they are used. It also provides a starting point for identifying and articulating the way that various concepts, priorities and assumptions are negotiated as part of the development process, and how this is often done implicitly through discussions about and changes made to the screenplay. I have found the notion of the boundary object particularly helpful in providing a conceptual framework for understanding, analysing and articulating the collective and negotiated nature of screenwriting and script development as a practice. 


\section{References}

Bernardin, M (2016) 'Working in Hollywood When You're Not White: Three Players Reveal All', in Hollywood Reporter, January 27th. Accessed 1/2/2017. Available at https://www.hollywoodreporter.com/features/workinghollywood-youre-not-white-859697

Bowker, G \& Star, S (2000), Sorting Things Out: Classification and Its Consequences, Cambridge, Mass. MIT Press

Bradley, C (2016) Skype interview with Rosamund Davies 23 March Buonanno, M (2015) Italian TV Drama: The Multiple Forms of European Influence. In I. Bondebjerg, E. Novrup Redvall \& A. Higson (Eds.) European Cinema and Television. Cultural Policy and Everyday Life (pp. 195-2013) Carrière, J-C (2013) Lecture SRC Bruxelles, September 2011, Journal of Screenwriting 4:2, pp. 117-122

Cotta Ramosino, L (2018) Lecture at International Screenwriting Conference, Milano, September

Cotta Ramosino, L (2019) Skype interview with Rosamund Davies 12 January Davies, R (2010) 'Screenwriting strategies in Marguerite Duras's script for Hiroshima, Mon Amour (1960)', Journal of Screenwriting 1: 1, pp. 149-173

Davies, R \& Flynn, R (2015) 'Explicit and Implicit Narratives in the Co-Design of Videogames', in Maragiannis, A. (Ed.) Final Paper/Proceedings of the Digital Research in the Humanities and Arts conference, DRHA2014, London. 
Duras, M (1960) Hiroshima, Mon Amour, scénario et dialogues, Paris: Gallimard

Duras, M (1966) Hiroshima, Mon Amour and Une Aussi Longue Absence (trans.

Richard Seaver and Barbara Wright) London: Calder and Boyars

Hiroshima, Mon Amour (1959) (Wr. Marguerite Duras, Dir. Alain Resnais, France/Japan, 91 mins)

Kjartansson, S (2016) Skype interview with Rosamund Davies 9 September MacDonald, I.W. (2004) Disentangling the Screen Idea. In Journal of Media Practice, 5: 2 (pp 85-99)

MacDonald, I. W. (2010) '... So it's not surprising I'm neurotic' The Screenwriter and the Screen Idea Work Group. In Journal of Screenwriting, 1:1 (pp 45-58) Maras, S (2009) Screenwriting: History, Theory, Practice, London: Wallflower Press

Mazin, C. (2018) (Presenter) Scriptnotes [Audio podcast] 18 March. Accessed 27 May 2018

Medici (Meyer, N \& Spotnitz, F (creators) 2016- )

Millard, K (2010) 'After the typewriter: the screenplay in a digital era', Journal of Screenwriting 1: 1, pp. 11-25

Millard, K (2014) Screenwriting in a Digital Era, Basingstoke: Palgrave Macmillan Moyersoen, S (2016) Skype interview with Rosamund Davies 19 September Munt, A. (2013), 'Expensive words, cheap images: 'Scripting' the adapted screenplay', Journal of Screenwriting 4: 1, pp. 57-76

Murphy, J.J (2010) 'No room for the fun stuff: the question of the screenplay in American Indie Cinema', Journal of Screenwriting 1: 1, pp. 175-196 
Murphy, J.J (2011) 'A similar sense of time: the collaboration between writer, Jon Raymond and director Kelly Reichardt in Old Joy and Wendy and Lucy', in Analysing the Screenplay, (Ed. Jill Nelmes) London: Routledge

Pasolini, P P (2005) Heretical Empiricism (2 ${ }^{\text {nd }}$ ed) (Ed, Louise K. Barnett, trans.

Ben Lawton and Louise K. Barnett) Washington D.C: New Academic Publishing LLC

Price, S (2010) The Screenplay: authorship, theory and criticism, Basingstoke:

Palgrave Macmillan

Rush, J \& Baughman, C (1997) 'Language as narrative voice: the poetics of the highly inflected screenplay' in Journal of Film and Video 49.3

Saha, A (2018) Race and the Cultural Industries, Cambridge: Polity Press Star, S.L \& Griesemer, J. R (1989) 'Institutional Ecology, 'Translations' and Boundary Objects: Amateurs and Professionals in Berkeley's Museum of Vertebrate Zoology, 1907-39'. In Social Studies of Science, 19:3 (pp. 387-420). Star, S. L (2010)

'This is Not a Boundary Object: Reflections on the Origin of a Concept'. In Science, Technology, \& Human Values, 35 (5) (pp 601-617)

Staiger, J (1985) 'The Hollywood Mode of Production, 1930-1960'. In The classical Hollywood cinema: film style \& mode of production to 1960 (Bordwell, D, Staiger, J \& Thompson, K) London: Routledge

Sternberg, C (1997) Written for the Screen. The American Motion-Picture Screenplay as Text. Tübingen: Stauffenburg Verlag

Ófærð/Trapped (Bradley, C, Moyersoen, S, Egilsson, Ó, Grimsson, J (Wrs.); Kjartansson, S, Zimmermann, K (Wrs. and Exec. Prods.); Kormákur, B (Series 
Creator, Exec. Prod., Dir.)

Zimmermann, K (2016) Skype interview with Rosamund Davies 31 May 